\title{
On the Tenability of Brute Naturalism and the Implications of Brute Theism
}

\author{
ThOmas D. SenOR \\ Department of Philosophy \\ University of Arkansas \\ Fayetteville, Arkansas
}

Timothy O'Connor's book Theism and Ultimate Explanation is a force to be reckoned with. ${ }^{1}$ Not only does it offer a defense of a new version of the cosmological argument but the argument comes embedded in a defense of nondeflationary modality and its role in both everyday and scientific explanation, and an epistemology of possibility and necessity. The arguments one finds in Theism and Ultimate Explanation are both philosophically and scientifically informed and in many cases highly original. In addition to these many virtues, Theism and Ultimate Explanation exemplifies one other greatmaking property as well as any book I can recall: authorial bravery. At pretty much every turn (and the book has as many turns as a two-lane highway in the Ozarks), O'Connor takes a position that is philosophically unpopular (he is an Aristotelian about causation, an agent-causation libertarian, and an emergentist in addition to being a theist who thinks that the existence of a contingent universe is a good argument for a necessarily existent deity). That he is able to defend these positions so ably is a testament to O'Connor's significant philosophical chops.

In this essay, I will comment on two places where I think O'Connor has not made his case in a compelling way. My two points concern the acceptability of a brute fact view of the universe and the implications of a contingent God. Regarding the former, I will argue that, contrary to what O'Connor claims, we have no good reason to prefer an account according to which the universe is contingent and explained via a necessary being to that of a natu-

AbSTRACT: Timothy O'Connor's book Theism and Ultimate Explanation offers a defense of a new version of the cosmological argument. In his discussion, O'Connor argues against the coherence of a brute fact "explanation" of the universe and for the claim that the God of theism cannot be logically contingent. In this paper, I take issue with both of these arguments. Regarding the former, I claim that contrary to what O'Connor asserts, we have no good reason to prefer an account according to which the universe is explained via a necessary being to that of a naturalist who thinks that the universe is contingent and ultimately unexplained. Regarding the latter, I argue that the possibility of a logically contingent God is fully consistent with traditional theism.

1. Timothy O'Connor, Theism and Ultimate Explanation: The Necessary Shape of Contingency (Malden, MA: Blackwell, 2008). 
ralist who thinks that the universe is contingent and ultimately unexplained. Regarding the latter, I will argue that, contrary to O'Connor's argument in the last chapter of his book, the possibility of a logically contingent God is fully consistent with traditional theism.

\section{On the Acceptability of a Brute Naturalism}

Although I stated at the outset that O'Connor presents a new version of the cosmological argument, that claim is arguable: it is not that there is doubt about O'Connor's originality but rather the degree to which he sees what he has done as presented an argument for what he terms "Logos"- that is, a necessary, personal being with highly unified properties whose creative power is the explanation of the existence of all contingently existing objects. At no point in Theism and Ultimate Explanation do we get anything that looks explicitly like an argument: that is, there are no marked premises from which a conclusion is derived. O'Connor is clear that he does not see what he is offering as a demonstration of a necessary being. The kind of argument we get from O'Connor is an inference to the best explanation. In order for the criticism that I will be pushing in this section to be clear, I will have to summarize the argument briefly (which turns out to be rather tricky).

The "traditional metaphysician's quest" is to find an "ultimate explanation of the most general features of the world we inhabit." Finding an explanation the details of which are knowable by us is unrealistic; what we can reasonably hope for, though, is an explanation schema or framework- that is, a broad outline that allows for the possibility of a "correct and complete" (ix) ultimate explanation. What we are looking for, O'Connor avers is, an answer to the existence question, his favored version of which is: Are there contingently existing objects and if there are why do these particular contingent objects exist and undergo the events they do? The traditional answer is that contingent objects exist and undergo the events they undergo because they are the products of the activity of a transcendent being who acts for reasons. In addition to the traditional answer, O'Connor considers the following possible alternatives: (i) a beginningless universe of contingent beings provides an adequate explanation for each being and hence the inference of a necessary being is unmotivated (Hume); (ii) the universe of contingent beings exists because it should (John Leslie and Derek Parfit); (iii) the universe is not contingent but necessary (Spinoza); and that (iv) the universe is the product of an impersonal, mechanistic necessary being (as opposed to a personal being who acts from reasons). Along the way, O'Connor also defends the coherence of the concept of necessary existence and rebuts the charge

2. Ibid., ix. 
that if the ground of all reality is a necessary being, then modality implodes and all beings (and events) are necessary.

The conclusion of the existence of a personal, transcendent necessary being is drawn from the fact that it best explains the world of contingent objects. Now it seems to me that what is striking about the argument as we have it is not so much what is on the list of alternative accounts that O'Connor considers but what is not. Surely the chief rival to the traditional answer, and the position most broadly accepted in the philosophical community, is not any of four listed above. The main alternative to theism is a naturalistic view that sees the universe as logically contingent but ultimately unexplained: in short, naturalism that adds that the existence of the universe is a brute fact. For ease of reference, let us call this view "brute naturalism." So why isn't this alternative to the traditional answer given its due?

O'Connor is not without an explanation. First, notice the form of the question that the traditional answer answers (O'Connor dubs this "the existence question"): Are there contingently existing objects and if there are why do these particular contingent objects exist and undergo the events they do? The naturalist will say that the first question has an answer ("yes") but the second question does not. And since a conjunctive question does not have an answer if one of its conjuncts has no answer, the brute naturalist is committed to thinking that the existence question is unanswerable. And since she does not provide an answer, her position is not one that needs to be ruled out when one is attempting to determine which answer to the existence question is best. Another way to appreciate this is that an inference to the best explanation argument is, after all, an inference to the best explanation. But if the naturalist does not offer an explanation for contingent reality, then she does not offer a candidate best explanation. So there is nothing arbitrary about O'Connor's failing to discuss in any detail the possibility of contingent, unexplained universe.

Still, granting that the exclusion of the brute naturalist position is not arbitrary is not to condone its absence. What is the reason for giving preference to positions that give a positive answer to the existence question? Why not include in the discussion the perspective that denies the existence question is answerable? After arguing that there is no chance there will be a naturalistic answer to the existence question and that there is no reason to think that the appeal to nonempirical factors in an ultimate explanation is "otiose, confused, vacuous, or in some other way impertinent or at the very least unseemly, coming from the lips of a modern thinker," $\mathrm{O}^{\text {'Connor says }}$ the following:

Now, prima facie, it seems unreasonable to say that the [existence] question is a perfectly coherent one, and that it correctly presupposes that the universe and everything therein need not have existence - that

3. Ibid., 69. 
is to say, its existence is entirely contingent-and nonetheless hold that there is no answer to it: hold that the universe's existence is simply a brute, unexplainable fact. It seems even more unreasonable, then to deny that, other things being equal, given two metaphysics such that one of them provides a final, nonarbitrary answer to the existence question and one of which leaves it unanswerable, we should prefer the one that answers it on account of its greater explanatory power. ${ }^{4}$

O'Connor's answer, then, to the question of why brute naturalism does not get more of a hearing is that it would be unreasonable (prima facie, anyway) to hold that the universe is contingent, that the existence question is coherent, and yet that brute naturalism is true. And it would be even more unreasonable to hold the contingency of the universe, the coherence of the existence question and yet not prefer a metaphysic that provided an answer to that question over one that did not since, clearly, the former would have greater explanatory power.

That each of these positions is unreasonable is not obvious. For I do not see why recognizing the coherence of the existence question carries with it the presumption that it has a positive answer. Consider an analogy: while walking in the woods, you come across four large stones at the base of a hill; the stones are so arranged that a parallelogram can be made from lines connecting the stones. Looking around you notice many other stones at the base of this hill but there is no other group of them that similarly can be used to form a standard geometric shape. It occurs to you to wonder whether these rocks were placed in their positions by someone who intended to outline a parallelogram or whether it is simply a matter of chance that the stones are where they are. So you ask yourself: why are these particular stones arranged as they are (call this "the position question")?

It should be noted that this case bears only an analogical relation to the case involving the existence question and the universe. For my stone case, there is no serious possibility that it is simply a brute fact that the stones are arranged as they are. Even if there is no agency behind their positions, there will be a causal explanation for each being where it is and there is nothing over and above the positions of the four stones that needs explaining. So in the stone case, broadly speaking, the choice is between there being an explanation involving agency (or maybe some other way of explaining the positions of the stones that does not imply that they are where they are "just by chance") and their having their positions just by chance. In the case of the universe, most broadly construed, the choice is between there being an explanation of the collection of contingent things, on the one hand, and there being no explanation of them on the other. Still, I think the stone analogy can be helpful so let us get back to it. 
Should I grant that the position question is coherent? I do not see why not. However, I might think it is ambiguous between "Why did someone so arrange the stones?" and "How did the stones come to be where they are?" If the former is the intended understanding of the question, then while I grant that it is coherent, it presumes too much and therefore if its assumptions are not true, then it may not have an answer. On the other hand, the second reading of the question makes no such assumptions and will have an answer even if it is only that it is purely by chance that the rocks are in that arrangement.

Let us look back now to the relevant part of the existence question: why do these particular contingent objects exist and undergo the events they do? Is this a coherent question? Sure, although it might be thought ambiguous in a way analogous to the question of the stone example. If it means "What is the explanation for why contingent objects exist and undergo the events they do?" (presuming that there is an explanation) then the question simply assumes the falsity of brute naturalism. It is, then, no wonder that brute naturalism does not get taken seriously as an alternative but that is just because it is ruled out of court without a hearing. On the alternative reading, the question is asking "Is there an explanation for why these particular contingent objects exist and undergo the events they do, and if there is, what is it?" This, too, is clearly coherent and presupposes only that contingent objects do exist (recall that the official formulation of the existence question begins with a question about whether there are contingent objects so it does not even really make this assumption). The key question now is whether it is prima facie unreasonable to grant the coherence of this question while thinking that the answer to it is no and whether it is "even more unreasonable" not to favor (other things being equal) an account that answers this question with a nonarbitrary, fundamental explanation over brute naturalism on the basis of the former's explanatory power.

I find the appeal to explanatory power odd in this context. For it is surely true that explanatory power is a significant virtue in a theory that accounts for phenomena for which there is clearly some explanation. But the brute naturalist is likely to be unmoved by an appeal to explanatory power regarding a phenomenon that she thinks has no explanation.

At bottom, the $\$ 64,000$ question is to what extent the bare existence of a contingent universe cries out for explanation. If it does loudly and clearly, then O'Connor is right that (other things being equal) a metaphysic that offers an explanation for it is to be preferred over one that does not. However, if the bare existence of a contingent universe is not in itself particularly surprising, then the presumption against brute naturalism is greatly diminished.

In concluding this section, let me just say that I do not find the bare existence of a contingent universe to be something that obviously needs explaining. Keep in mind, that what we are talking about here is the bare existence of a contingent universe. There may be features of the universe that 
do clearly beg for explanation (its being fine-tuned for life, say), but the fact that there is something contingent rather than nothing at all does not strike me as one of them.

\section{The Possibility of Brute Theism}

Having argued that brute naturalism has not been shown to be unreasonable on the grounds that O'Connor claims, I want to conclude by considering what I hereby dub "brute theism"- the claim that the universe was freely created by a contingent God.

O'Connor clearly thinks that to adopt brute theism is to give up much of what is important in Christian theism (and perhaps theism in general). He claims that "the concept of God implicit in certain claims at the heart of the Biblical revelation themselves require articulation in the metaphysical terms of necessary being" and ". . . any minimally acceptable understanding of God's sovereign control over what happens in the world implicitly requires the concept of necessary being."

These are strong assertions that I think are incorrect. In what follows I will briefly sketch a form of brute theism that is quite traditional and which hence does not suffer from the debilitating liabilities that concern O'Connor. From here on out, let "brute theism" refer to the view sketched below.

According to brute theism, God exists contingently. We must be careful, though, to make clear the type of contingency at issue. To call a being "contingent" in the relevant sense (and this is the sense that O'Connor means) is to say that there are possible worlds at which it does not exist. But it does not follow from this variety of contingency that the being's existence is contingent on the causal activity of other beings. Surely, this latter kind of contingency is inconsistent with standard theism: God is not ontologically beholden to anyone or anything. Still, brute theism gets its name from its claim that the existence of God is the ultimate (and only) brute fact - there is no explanation for God's existence and God's nonexistence is possible.

Even so, the brute theist will maintain both that God's going out of existence is not a possibility and that the existence of all other contingent entities is (fundamentally) explained by the causal activity of God. But even more: God is the only possible source of being and power. That is, necessarily, God is the only source of being - every object that could be is causally and ontologically dependent on God (except God himself, of course). This implies that there is but a single world at which God does not exist since with the exception of God himself, no contingent being exists unless it was created by God.

5. Ibid., 132, 143 (emphasis in original). 
Brute theism insists on the following schema of modalized claims regarding the standard divine attributes: "Necessarily, God is $P$ " and "God is necessarily $P$." That is, brute theism asserts that for omnipotence, omniscience, omnibenevolence, and the rest, it is both true that nothing can be God and lack one of those properties and that the being who is God has those properties essentially.

Let us now take a quick look at the claims O'Connor makes against divine contingency:

(1) "If God is not a necessary being ... then it is possible that there is a being which neither owes its existence to Him nor derives its power from him. From this it follows that, possibly, there is a being over which God has no causal control."

Reply: Not at all. Brute theism claims that God is the causal source of all that there is or could be.

(2) "If [God exists contingently], it may turn out to be the case that the only objects ever to appear on the scene are those to which He gives being. But if it does so turn out, that is a contingent fact whose truth He did not (and could not) ensure." 7

Reply: Not at all. The fact that an object exists contingently does not mean it could exist apart from that which actually brought it about: my existence is contingent but I could not exist in a world that fails to contain my parents. So it is with all contingent beings save God: every world in which they are not the products of God's creative activity is a world in which they are not.

The only one of O'Connor's objections that might cause a problem for brute theism is this:

(3) "[If brute theism were true], it seems, [God] could sensibly feel fortunate that He happens to exist, even though He owes His existence to no existing thing. And that appears to be inadequate, clearly at odds with how ordinary theists implicitly regard God's ontological status." 8

Reply: Should the God of brute theism feel fortunate for existing? Maybe. But there is no one to whom God should feel gratitude for his good fortune and his continued existence is not something for which he is fortunate. The idea that God should feel fortunate also seems to invite a crude kind of anthropomorphism that is not otherwise a part of brute theism.

Finally, I take issue with the claim that the implication that God would feel fortunate to exist is "clearly at odds with how ordinary theists implicitly regard God's ontological status." O'Connor must attend a very philosophi- 
cally sophisticated church. I am pretty sure that I have never been a member of a congregation in which most of the members implicitly reject brute theism and embrace full-on Anselmian theism. It is not that they reject Anselmianism but rather that (as best I can tell) their philosophical theology does not distinguish between the views. They are committed to a God who is creator of heaven and earth, for whom all things are possible, and whose ways are not our ways. Brute theism can see all of this and raise it the necessary dependence of all existing (and possible) things upon God and God's essential omnipotence, omniscience, and omnibenevolence. Ordinary theists will be just fine with this. 